\title{
BILATERAL OVARIAN MASS COMPLICATING PREGNANCY
}

\author{
Arjumand Bano ${ }^{1}$, Triveni J ${ }^{2}$
}

\section{HOW TO CITE THIS ARTICLE:}

Arjumand Bano, Triveni J. "Bilateral Ovarian Mass Complicating Pregnancy". Journal of Evolution of Medical and Dental Sciences 2015; Vol. 4, Issue 51, June 25; Page: 8947-8949, DOI: 10.14260/jemds/2015/1297

ABSTRACT: A 22 years old patient with 9 months of Amenorrhoea with a abdominal swelling was admitted to our institution with an Ultrasonography report of Bilateral ovarian mass $(14.3 \times 5.9 \mathrm{~cm}$ in left ovary) and $(9.5 \times 7 \mathrm{~cm}$ in right ovary) with internal vascularity with septations along with single live intrauterine fetus. She delivered by elective caesarean section in V/O breech presentation. Left side ovarian cystectomy done Right side ovarian puncture done. Histopathology showed left sideMucinous cystadenoma. Right Side-Follicular cyst. Mucinous cystadenomas are benign epithelial ovarian tumors which tend to be unilateral, bilateral and multilocular with smooth surface and contain mucinous fluid, $75 \%$ of all mucinous tumors are benign, while $10 \%$ are borderline and $15 \%$ are invasive carcinomas. Benign mucinous tumors are most common in the third to fifth decades of life and may be $20-30 \mathrm{cms}$ in size. The incidence of ovarian cysts during pregnancy is less than $5 \%$ and most of them are benign in nature. Giant cysts found in less than $1 \%$ of the cases of ovarian cysts with pregnancy.

KEYWORDS: Mucinous cystadenoma, Pregnancy, Ovarian Mass.

INTRODUCTION: Ovarian mass greater than $5 \mathrm{cms}$ are rare during pregnancy according to recent epidemiological studies on ovarian cysts during pregnancy one out of 600 are in most cases benign neoformations. The most frequent histological type reported is mature cystic teratoma $(50 \%$ of the cases) followed by functional cysts (13\%) benign cystadenomas (20\%) and ovarian cancer (0.6\%).

Mucinous cystadenomas are benign epithelial ovarian tumors which tend to be unilateral, bilateral and multilocular with smooth surface and contain mucinous fluid, $75 \%$ of all mucinous tumor are benign, while $10 \%$ are borderline and $15 \%$ are invasive carcinoma. mucinous tumors are most common in the third to fifth decades of life and may be $20-30 \mathrm{cms}$ in size. ${ }^{1}$

The incidence of ovarian cysts during pregnancy is less than $5 \%$ and most of them are benign in nature, Giant cyst are found in less than $1 \%$ of cases of ovarian cysts with pregnancy. ${ }^{2}$ Torsion is the most common and serious complication of benign ovarian cysts during pregnancy. The cyst may rupture in the peritoneal cavity due to torsion. ${ }^{3}$

Understanding of benign nature and uncomplicated course of ovarian masses diagnosed incidentally by ultrasound has led to a more conservative but careful and vigilant approach to management of ovarian masses in pregnancy.

Abortion is a common complication of abdominal surgery in first trimester, and in second trimester intrauterine growth restriction and preterm labor can occur. Laparotomy in series was not associated with any obstetric complication. ${ }^{4}$ Although second trimester surgery is safe and ideal, it has increased risk of adverse pregnancy outcome hence, surgical management needs to be reconsidered. ${ }^{5}$

The most common benign adnexal masses during pregnancy are cystic teratomas (36\%). Followed by cystadenomas. ${ }^{6}$ Yenicesu GI et al. and Qublan HS et al. ${ }^{7}$ both described removal of ovarian mucinous cystadenomas weighing around $6 \mathrm{~kg}$ after caesarean section. ${ }^{8}$ 


\section{CASE REPORT}

In the reported cases however either the cysts were removed during pregnancy or the baby delivered by Caesarean section along with the removal of cyst.

CASE DESCRIPTION: A 22 years primigravida at 36 wks with breech presentation, she was diagnosed to have bilateral ovarian mass $(14.3 \times 5.9 \mathrm{~cm}$ in left side; $9.5 \times 7 \mathrm{~cm}$ in right side) with internal vascularity and septation at 28 wks of pregnancy. She was followed up conservatively till term she underwent planned cesarean section for breech presentation. Left side ovarian cystectomy done and right side ovarian puncture was done. Histopathology showed left side mucinous cystadenoma and right side follicular cyst.

CONCLUSION: Ovarian masses are frequently diagnosed during pregnancy. The majority of these all functional ovarian cysts which resolve spontaneously by the second trimester. Even long persistent masses with malignancy is rare and restricted criteria for ultrasound \& tumor markers for diagnosis of malignancy should be kept in mind. Ideal time for scheduled surgery is beginning of second trimester. In selected cases ovarian masses can be followed till term and surgery can be perfomed during caesarean delivery.

If the ovarian mass is complicated with torsion, rupture or obstruction immediate surgery is to be performed irrespective of gestational age with risk of abortion or prematurity and fetal morbidity.

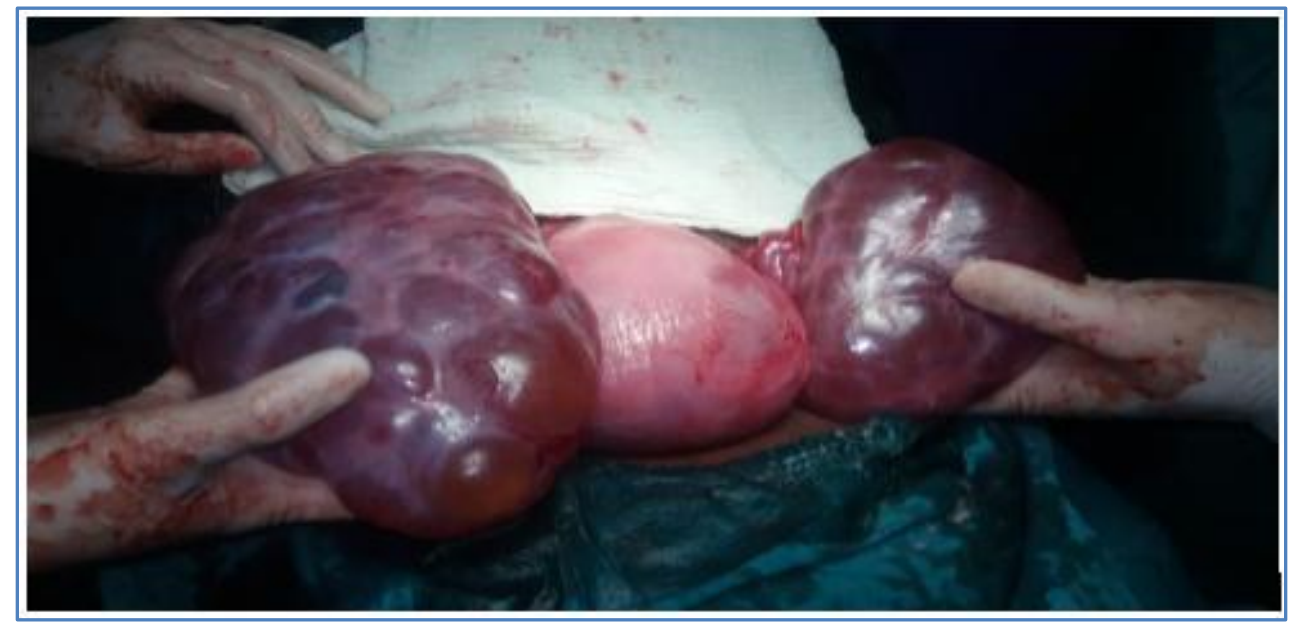

Fig. 1: Bilateral ovarian mass along with Uterus

\section{REFERENCES:}

1. Ioffe OB, Simsir A. Silverberg SG. Pathology. In: Brerek JS Hacker NF, editors practical Gynaecologic Oncology $3^{\text {rd }}$ ed. Philadelphia: Lippincott Williams \& wilkins company; 2000. pp. 213-4.

2. Rosales Aujang E. Giant ovarian cyst and pregnancy. Case report and literature review. Ginecol Obstet Mex. 2011; 79: 235-8. PubMed PMID: 21966812. Spanish. [PubMed]

3. Parker LP. Ovarian tumors complicating Pregnancy. In Rock JA, Jones HW, editors. Telinde's operative gynaecology.9thed. Philadelphia: Lippincott Williams \& Wilkins Company; 2003. pp 846-56. 


\section{CASE REPORT}

4. Zanetta G, Mariani E, Lissoni A, Ceruti P, Trio D, Strobelt N, Mariani S. A Prospective study of the role of ultrasound in management of adnexal masses in pregnancy. BJOG 2003; 110: 578-583.

5. Whitecar MP, Turner S, Higby MK, Adnexal masses in pregnancy: A review of 130 cases undergoing surgical management. Am J Obstet Gynecol 1999; 181: 19-24.

6. Bignardi T, Condous G. The management of ovarian pathology in pregnancy. Best pract Res Clin Obstet Gynecol 2009; 23: 539-548.

7. Yenicesu GI. Cetin M, Arici S. A huge ovarian mucinous cystadenoma complicating pregnancy.a case report. Cumhuriyet Medical Journal. 2009; 31: 174-7.

8. Platek DN, Henderson CE, Goldberg GL. The management of a persistent adnexal mass in pregnancy. Am J Obstet Gynecol 1995; 173(4): 1236-1240.

\section{AUTHORS:}

1. Arjumand Bano

2. Triveni J.

\section{PARTICULARS OF CONTRIBUTORS:}

1. DGO, Department of Obstetrics \& Gynaecology, Chalmeda Anand Rao Institute of Medical Sciences, Bommakal, Karimnagar.

2. Post Graduate, Department of Obstetrics \& Gynaecology, Chalmeda Anand Rao Institute of Medical Sciences, Bommakal, Karimnagar.

FINANCIAL OR OTHER COMPETING INTERESTS: None

\section{NAME ADDRESS EMAIL ID OF THE} CORRESPONDING AUTHOR:

Dr. Triveni J,

Room No. 523, Girls Hostel,

Chalmeda Anand Rao Institute of

Medical Sciences, Bommakal, Karimnagar,

Telangana.

E-mail: dr.triveni99@gmail.com

Date of Submission: 27/05/2015.

Date of Peer Review: 28/05/2015.

Date of Acceptance: 17/06/2015.

Date of Publishing: 25/06/2015. 